\section{Australian tribute to the late Sir Aubrey Lewis}

DeAr SIR,

British members of the College may be interested to know that on 5 November 1981 a memorial plaque in honour of the late Sir Aubrey Lewis was unveiled in the University of Adelaide. Sir Aubrey Lewis graduated from the Medical School of the University in 1923, and his Doctorate was also conferred by this University.

The ceremony was sponsored by the South Australian Branch of the Royal Australian and New Zealand College of Psychiatrists, the University of Adelaide and the Australian Society for Psychiatric Research, and was attended by representatives of the South Australian Association for Mental Health. The Vice-Chancellor, Professor Donald Stranks, accepted the plaque from the South Australian Branch of the RANZCP.

Mr J. Estcourt Hughes, a distinguished Adelaide surgeon, medical historian and contemporary of Sir Aubrey, spoke of his early recollections of him, and Professor G. Allen German, Professor of Psychiatry in the University of Western Australia, who had trained under Sir Aubrey, noted his later achievements and then delivered the academic address of the Australian Society for Psychiatric Research.

Fittingly, the plaque is placed in the foyer of the Florey lecture theatre. Lord Florey was also a distinguished Adelaide graduate and a contemporary of Sir Aubrey. The inscription on the plaque reads:

Sir Aubrey Lewis

$L L D, D S c, M D, F R C P, F R C P$ sych 1900-1975

"A graduate in medicine of this university, Sir Aubrey Lewis was the first professor at the Institute of Psychiatry, University of London (1946-66). He was the leading figure in British Commonwealth Psychiatry in the mid-20th century era, exerting great influence through his scholarship and inspirational qualities."

ROBERT D. GOLDNEY

Issy Prowsky

Royal Australian and New Zealand

College of Psychiatrists, South

Australia Branch

Issy Pllowsky

\section{A new College Group for swicide?}

DeAr Sir,

I am wondering whether there is any general support in the College for setting up a group for the study of suicide/suicide prevention/crisis intervention along the lines of the Dependence/Addiction and Biological Psychiatry Groups.

Such a Group might help to improve medical education and training in this field, as well as stimulating research. It might also encourage the Department of Health and the Medical Research Council to give rather more priority to research into suicide and attempted suicide-and to their prevention than is now the case.

\section{Addenbrooke's Hospital Cambridge}

R. GARDNER

\section{British psychiatrists bewarel}

\section{DeAR Sir,}

I write as a member of the College who has chosen permanently to reside and practise psychiatry in Australia (since) 1974), but I have noticed certain subtle changes in attitude towards 'foreign' psychiatrists that are now becoming more evident through recent actions by the local College of Psychiatrists, which I believe should be brought to the notice of UK psychiatrists contemplating a career 'down under'.

Firstly, the local College: the Royal Australian and New Zealand College of Psychiatrists (RANZCP) has recently decreed that, as from July 1982, only its Members will be accredited as supervisors of psychiatric registrars. I understand that this does not prevent non-RANZCP psychiatrists from being the clinical 'chief' in charge of registrars, but one can envisage awkward and possibly embarrassing situations developing in the professional relationship between senior and junior, where the imparting of clinical skills and knowledge during, for example, ward rounds is regarded by the local College as having no apparent validity in the registrar's total training programme.

Secondly, a 'foreign' psychiatrist who wishes to practise as a private psychiatrist must first obtain Specialist recognition for the purposes of the Health Insurance Act (1973). Each State has a Specialist Recognition Advisory Committee which processes applications from doctors for recognition as a Specialist for the purpose of payment of medical benefits to patients under the health insurance arrangements currently operating in this country. To aid this Committee in each State, a Federal Committee-The National Specialist Qualification Advisory Committeepublishes annually a list of medical qualifications which are acceptable higher qualifications for Specialist recognition. Many of these qualifications are subject to certain provisos, and the current entry for the MRCPsych reads: 'Acceptable if obtained before 1 January 1982 and subject to approval of training'. The State Specialist Recognition Advisory Committees then refer an applicants' credentials and details of training, etc., to the RANZCP for their opinion/advice concerning 'approval of training'. It can be seen that, in this fashion, the local College can 'control' the entry of 'foreign' psychiatrists into private practice; indeed, they could be instrumental in diverting such psychiatric manpower into less attractive areas of practice (e.g. Govern- 